\title{
Ultrasonic Dispersion of Nanocarbons in Soil-water Mixture
}

\author{
Mohd Raihan TAHA ${ }^{1}$, Jamal M.A. ALSHAREF ${ }^{1}$ *, Tanveer Ahmed KHAN ${ }^{3}$, \\ Ramez A. Al-MANSOB ${ }^{4}$, Maryam GABER ${ }^{1}$
}

\author{
${ }^{1}$ Department of Civil and Structural Engineering, Universiti Kebangsaan Malaysia (UKM), 43600 Bangi, Selangor, \\ Malaysia \\ ${ }^{2}$ Institute for Environment and Development (LESTARI), Universiti Kebangsaan Malaysia (UKM), 43600 Bangi, Selangor, \\ Malaysia \\ ${ }^{3}$ Civil Engineering Department BZU, Multan, Pakistan \\ ${ }^{4}$ Faculty of Engineering, Technology \& Built Environment, UCSI University, 56000 Cheras, Kuala Lumpur, Malaysia \\ crossref http://dx.doi.org/10.5755/j01.ms.26.1.19608
}

Received 05 April 2018; accepted 15 December 2018

\begin{abstract}
Nanocarbons (NCs) are a novel reinforcing material used to improve the mechanical properties of composite materials. As an application of this technology, research has been considering how nanocarbons can been used in soil reinforcement. However, to take advantage of the excellent reinforcing capabilities of nanocarbon tubes (CNTs) and nanocarbon fibers (CNFs), it is necessary to achieve a uniform distribution of nanocarbons in the composites. This paper presents a novel method for improving the dispersion of CNTs and CNFs in soil. The approach incorporates soil itself to stabilize the distribution of CNTs and CNFs. To examine the effectiveness of the method, specimens of soil with CNTs and CNFs were prepared with different concentrations of water. The specimens were then sonicated with ultrasonic equipment and imaged by field-emission scanning electron microscopy (FSEM) and transmission electron microscopy (TEM). The results showed that soil containing sufficient proportions of micro-particles (clay) can itself largely prevent the reagglomeration of NCs in the soil, thereby stabilizing their dispersion.

Keywords: nanocarbons, dispersion, soil, ultrasonic, microstructure.
\end{abstract}

\section{INTRODUCTION}

When compared to more traditional fibers, nanocarbons (NCs), in the form of nanocarbon tubes (CNTs) and nanocarbon fibers (CNFs), hold several featured advantages as a reinforcing material for high-strength/performance cement paste as well as for many other composites. Firstly, they feature greater strength and stiffness [1], which results in improved overall mechanical behaviour. Secondly, their aspect ratio up to $132,000,000: 1$, is significantly more than any other material. This ideal one-dimensional structure of carbon atoms [2] is expected to effectively arrest nanocracks as much higher energies would bedemanded to support crack propagation. Thirdly, provided that nanocarbons (NCs) are uniformly dispersed, due to their nanoscale diameter, fiber spacing is reduced [3]. CNFs have an average diameter of $70-200 \mathrm{~nm}$ and an average length of $50-200 \mu \mathrm{m}$, whereas CNTs have an average diameter range of $<1 \mathrm{~nm}-50 \mathrm{~nm}$ and an average length of $1 \mu \mathrm{m}-1 \mathrm{~cm}$. The strength of NCs are 100 times that of steel, but at only $1 / 6$ th of steel's specific gravity [4]. Values as high as $60 \mathrm{GPa}\left(8.7 \times 10^{6} \mathrm{psi}\right)$ for ultimate strength and $6 \%$ for ultimate strain have been reported [5]. Moreover, research has been conducted investigating the potential of using CNTs and CNFs in environmental protection applications. These investigations have sought to use CNTs as selective sorbents for the removal of organic/biological contaminants such as carcinogenic cyanobacterial microcystins from water streams [6]. Furthermore, because of ongoing advancements in the industrialization and mass production of these nanofilaments, their prices are decreasing rapidly [7]. The conventional synthesis methods used for large scale CNT and CNF production, can keep the production cost low [8].

Research has shown that CNTs and CNFs can improve mechanical properties such as tensile and compressive strengths significantly. However, in practical applications such as in concrete systems, the projected improvements are rarely achieved. The main reason posited for failure to achieve expected improvements is the poor dispersion of CNTs and CNFs in the cement paste [9]. The dispersion behavior of CNTs and CNFs depends on a few critical factors such as length of nanomaterials, entanglement density, volume fraction, duration of sonication, and attractive forces [10]. Attraction due to strong van der Waals forces between NC filaments leads to their agglomeration, which afterwards, are very difficult to disentangle or disperse. To overcome this dispersion problem, researchers have been investigating chemical methods as a means of achieving homogeneous dispersion of NC materials in water and various polymers. Methods being investigated include the use of chemicals. These chemical methods can be used in conjunction with physical methods (such as ultrasonication), which can result in immediate dispersion of NC materials. However, most effective surfactants are not compatible with soil material [11] or cement hydration, and their presence in cement paste usually results in a weak material in which significant quantities of air is entrapped.

\footnotetext{
* Corresponding author. Tel.: +60 1137086965.

E-mail address: jamalshref@yahoo.com (J.M.A. Alsharef)
} 
If not controlled properly, it can damage, shorten, or even dissolve the NC material $[12,13]$.

When clay minerals are added to polymers, salts or surfactants, different effects on the electrokinetic and rheological properties of suspensions will occur due to the interactions between the clay particles and the ions or molecules [14]. When surfactants molecules are placed between the layers of clay by H-bond formation, this may reduce the electrostatic interactions between the clay particles, thereby reducing the zeta potential of the system [15]. Moreover, when surfactants are used in soil, they are involved in an increased chemical concentration, thus reducing the thickness of the double layer. This results in the particles coming closer together thereby causing the net force to be attractive [16]. In this environment, the particles flock toward each other randomly forming loose arrays, thus resulting in a flocculated structure. Such a soil structure eventually results in an increase in pore or void spaces through which fluids can pass, thus increasing the permeability of the soil [11]. Therefore, to avoid air entrapment concerns, experimental investigations have been conducted into physically treating and using of the soil itself to stabilize the distribution of CNTs and CNFs in the soil.

The use of ultrasonication reported to effect considerable dispersion of nano-particles in aqueous solutions is frequently achieved. In particular, it has been shown that CNTs and CNFs can be effectively ultrasonically dispersed in a water solution [17]. The sonication process disperses both soil and NCs concurrently and the favorable distribution of soil and NCs causes them to intertwine with each other. Small soil particles of submicron size act as wedges between the CNTs/CNFs and soil, thus physically restraining their motion. In keeping the $\mathrm{NC}$ particles far enough apart, it renders the inter-fiber attractive forces ineffective, thus stabilizing the dispersion and distribution of the CNTs and CNFs in soil.

Yazdanbakhsh and Grasley [18] have suggested the incorporation of silica fume (nanometer-sized particles of amorphous silica) with surfactant to improve the dispersion of CNFs in hardened cementitious materials. The aim of this experimental study was to demonstrate that soil with a fraction of $23 \%$ clay (particles less than $1 \mu \mathrm{m}$ ) can be used to effectively stabilize the dispersion of CNTs and CNFs in the soil composite.

\section{EXPERIMENTAL}

\subsection{Materials and techniques}

A residual soil from Universiti Kebangsaan Malaysia, Bangi campus was chosen as the sample soil for the study. This soil, termed UKM soil, was sampled one meter below the surface. According to the Unified Soil Classification System, the UKM soil is classified as sandy clayey (SC). Two types of NCs were selected, multiwall carbon nanotube (CNT) and carbon nanofiber (CNF) with commercial names Graphistrength C100 and PR-24-XT-LHT, respectively. Distilled water was used to prepare solutions.

For the sonication process, the ultrasonic equipment Sonic Ruptor 250 Ultrasonic Homogenizer from the USA was used. A piezoelectric ultrasonic transducer transforms a sinusoidal electrical voltage into a mechanical longitudinal resonance vibration with the resonance frequency of $20 \mathrm{kHz}$. The ultrasonic tip used had a cylindrical-shaped medium-intensity ultrasonic processor with a diameter of $19 \mathrm{~mm}$ and length of $10.5 \mathrm{~cm}$. the device is able to treat volumes in the range $25-500 \mathrm{ml}$, and was operated at $50 \%$ of its maximum amplitude, delivering energy to the samples at a rate of $1900-2100 \mathrm{~J} / \mathrm{min}$. Energy was applied in cycles of 2 seconds to prevent the suspensions from overheating.

An electronic $\mathrm{pH}$ meter was used to determine the $\mathrm{pH}$ of the UKM soil and to measure the change in $\mathrm{pH}$ due to sonication with NCs. The $\mathrm{pH}$ tests were conducted according to the ASTM D 6276 standard. Organic matter contains carbon, which may occur in complex chain compounds with hydrogen, oxygen, nitrogen and other elements. The ASTM D 2974 test procedure was followed to determine the organic matter present in the soil. An electric muffle furnace capable of maintaining a temperature of $440 \pm 25^{\circ} \mathrm{C}$ was used to burn the sample until all the organic matter was ashed, after which time, continued exposure to the furnace environment does to result in any more burning, and consequently, does not result in additional reduction in the soil's weight. The organic matter as a percentage can be then calculated as

$$
\begin{aligned}
& \% \text { Organic matter } \\
& =\frac{\text { oven dried weight }- \text { furnace dried weight }}{\text { oven dried weight }} \times 100 \text {. }
\end{aligned}
$$

\subsection{Preparation and identification}

Dispersion solution was prepared by mixing $50 \mathrm{~g}$ of soil with distilled water. Soil-to-water weight ratios of 1:1, 1:2 and 1:4 were selected to assess the influence of water-filled volumes between soil particles on the movement of NCs. The amounts of NCs used with different soil-to-water ratios are given in Table 1.

Table 1. Proportions of the UKM soil and NC mixture with deferent soil-to-water ratios.

\begin{tabular}{|c|c|c|c|}
\hline Mix & Soil to water ratio & CNT\% to soil & CNF\% to soil \\
\hline 1 & $1: 1$ & 1.0 & - \\
\hline 2 & $1: 2$ & 1.0 & - \\
\hline 3 & $1: 4$ & 1.0 & - \\
\hline 4 & $1: 1$ & - & 1.0 \\
\hline 5 & $1: 2$ & - & 1.0 \\
\hline 6 & $1: 4$ & - & 1.0 \\
\hline
\end{tabular}

The NCs were added to the water-soil solution and manually mixed for 5-10 minutes was and the mixture then covered and left for 24 hours allowing clay particles (particles smaller than $1 \mu \mathrm{m}$ ) to become fully saturated. The solution was then sonicated for $4 \mathrm{~min}$ as preliminary investigations have shown that 4 minutes of sonication is sufficient to disagglomerate the NCs while avoiding possible tube fragmentation [19]. This time is also sufficient and accomplish dispersal of soil in the aqueous solution [20], while preventing the suspensions from overheating [21]. The sonication process disperses both soil and NCs concurrently, while a wide distribution of soil particles and $\mathrm{NCs}$ results in them overlapping with each other as submicron clay particles act as wedges between the NCs and other soil particles. After preparation, the specimens were 
divided into two sets to investigate the interaction of NCs. For the first set of samples, transmission electron microscopy (TEM) is used to observe the interactions, while for the second set, the samples were oven-dried at $110 \pm 5^{\circ} \mathrm{C}$ for 24 hours before observing the interactions of NCs and soil particles with advanced instruments such as field-emission scanning electron microscopes (FESEM).

\section{RESULTS AND DISCUSSION}

Photos of the samples, before and after manual mixing (but before sonication), are shown in Fig. 2.
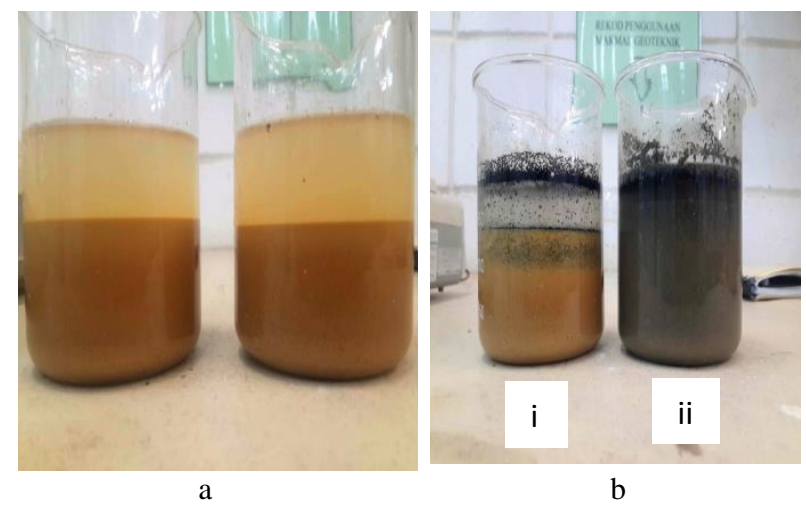

Fig. 2. a-soil mixed with water; $b$-after manually mixing of NCs; i-CNTs; ii-CNFs

It clearly shows that the manually-mixed samples have the greater portion of micro-particles of NCs at the top and clay at bottom. Fig. 3 shows that after sonication for 4 minutes, the soil seems well-mixed, forming a homogeneous and uniform-color mixture, thus implying that the NCs are in close association with the soil particles for all soil-to-water ratios.

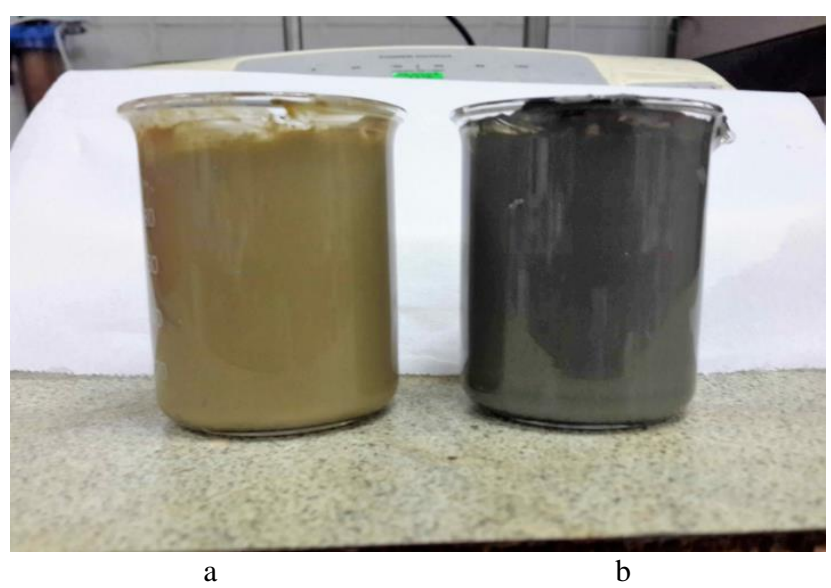

Fig. 3. UKM soil with: $a-C N T ' s ; b-C N F$ 's after 4 min sonication

This clearly contrasts with the separation between the NCs and clay minerals before sonication as shown in Fig. 2. After 5 minutes of manual mixing, the movement of the $\mathrm{NCs}$ was reduced and more agglomeration occurred, possibly due to the formation of hydration products and the onset of settling. Fig. 4 shows pictures of different soilwater mixtures 30 days after sonication. It is evident that the solution was well-stabilized and well-dispersed even after 30 days. As mentioned previously, it is apparent that nanofilaments can't move freely in soil-water mixture.
However, by increasing water-filled volumes between soil particles and nanofibers, overlapping will occur (by well dispersion). On the other hand, Van der Waals forces prevent the nanofilaments to reagglomerate in all water ratios, resulting in distribution of $\mathrm{NCs}$ in soil after sonication as shown in Fig. 5.

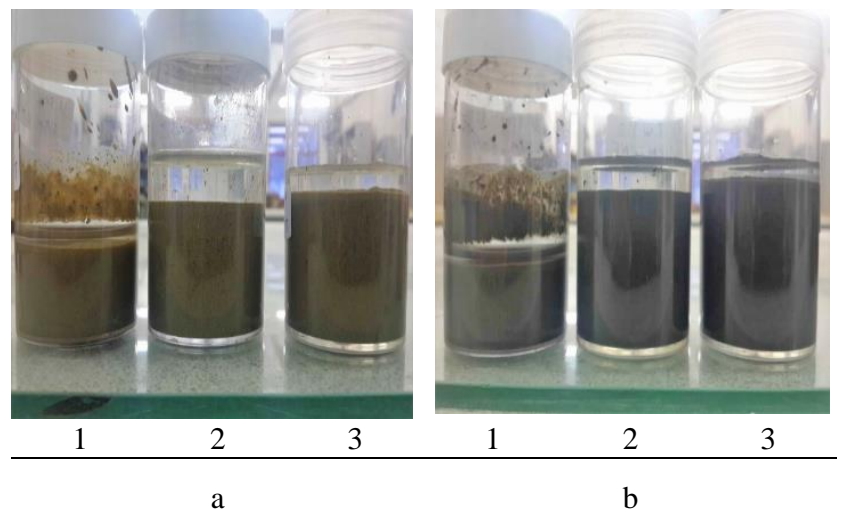

Fig. 4. Dispersion of: $\mathrm{a}-\mathrm{CNTs}$; $\mathrm{b}-\mathrm{CNF} 30$ days after sonication in different soil-water ratios; 1:1, 1:2, and 1:4 shown in 1, 2 and 3 , respectively

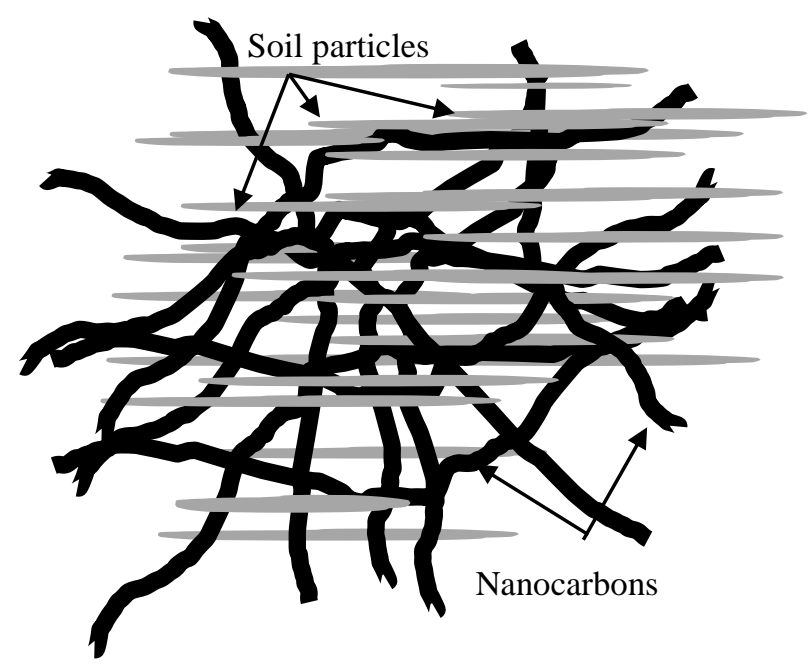

Fig. 5. Schematic diagram showing the progression of distribution of NCs in soil after sonication

\subsection{Morphology}

FESEM observations of the manually-mixed NCs and soil mixture, prior to sonication are shown in Fig. 6. Poor dispersion of CNTs and CNFs can be seen clearly in the form of bundles and lumps of two materials. Similarly, the clay fraction of the soil was agglomerated. FESEM images of the NCs and soil mixture after 4 mins of sonication are shown in Fig. 7. Image Fig. 7 a shows a very uniform and thoroughly-mixed NCs and soil mixture. Furthermore, the higher resolution images Fig. b, c and d display bridging and wrapping of NCs with soil particles. Because of the relatively widespread dispersion of NCs, a higher magnification lens was used to obtain images that were representative of the extent of dispersion in the soil mixture. Because of the bridge-connecting effect of NCs, they positively fulfill the role of bridges across cracks and voids, thereby guaranteeing load-transfer when tension is present in the system [22]. 

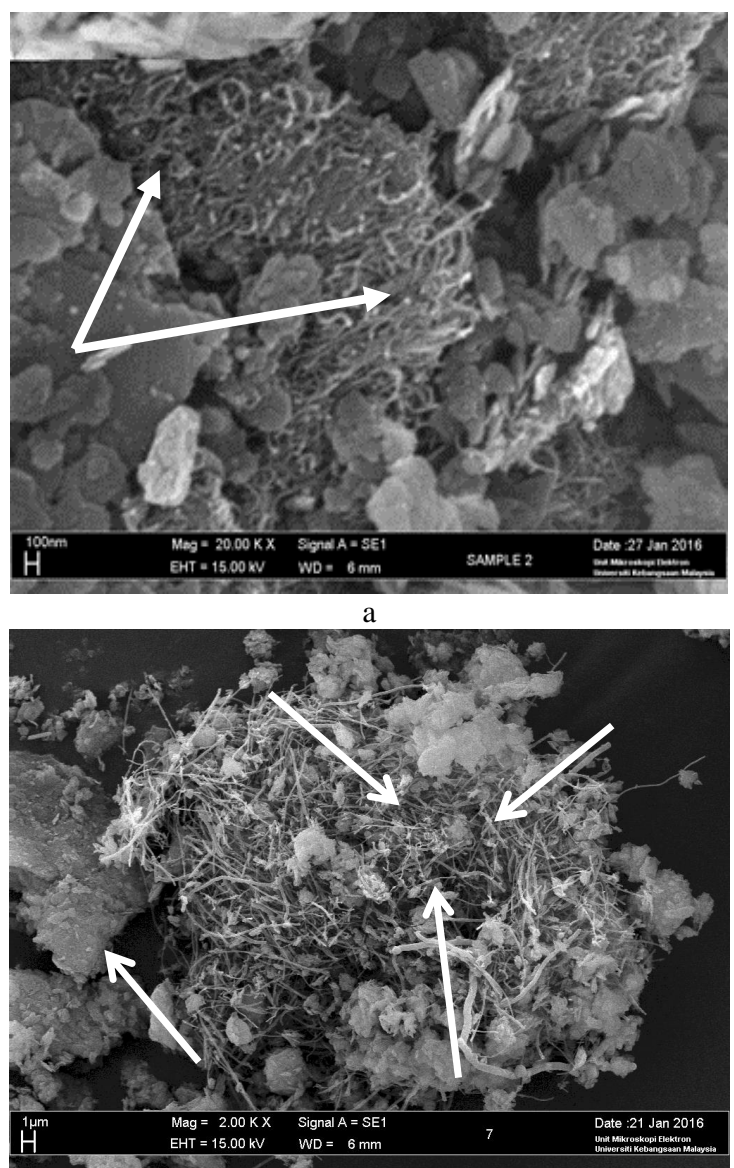

b

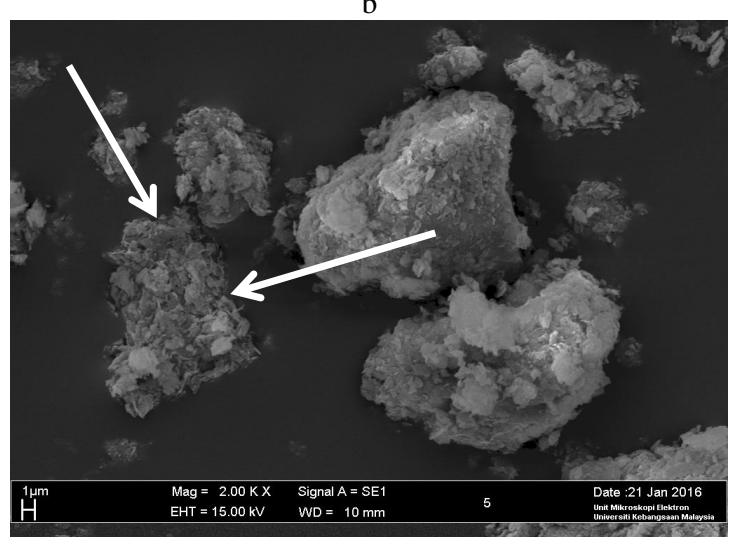

Fig. 6. FESEM images of soil and NCs after manual mixing: $\mathrm{a}$-agglomerated CNTs; b-agglomerated CNFs; $\mathrm{c}$-agglomerated soil

However, CNFs have a larger aspect ratio than CNTs, and so a larger bond area in soil composite can be obtained, leading to a strong bonding between CNFs and the soil. Therefore, it can ensure good load-transfer efficiency from the soil particles to NCs in the case of tension [23]. As a consequence, the tensile and compressive strengths of soil are enhanced. However, the bonding force between the fibers and the soil matrix may be low if mixing is not done properly, as was the case with manual mixing. The CNFs show more workability because their size is larger than CNTs, as shown in FESEM images, in Fig. $7 \mathrm{c}$ and $\mathrm{d}$.

In order to confirm the dispersion of soil particles with CNTs and CNFs, TEM investigation was carried out on the mixtures with observations being taken 30 days after sonication.

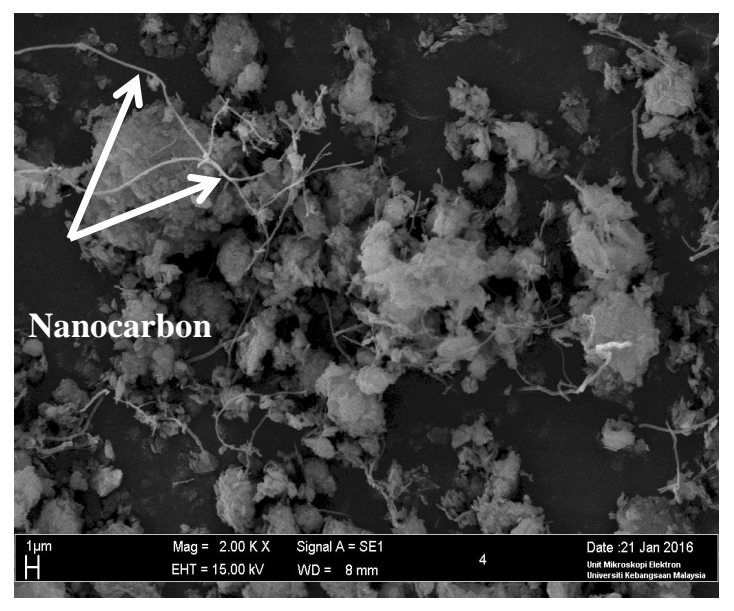

a

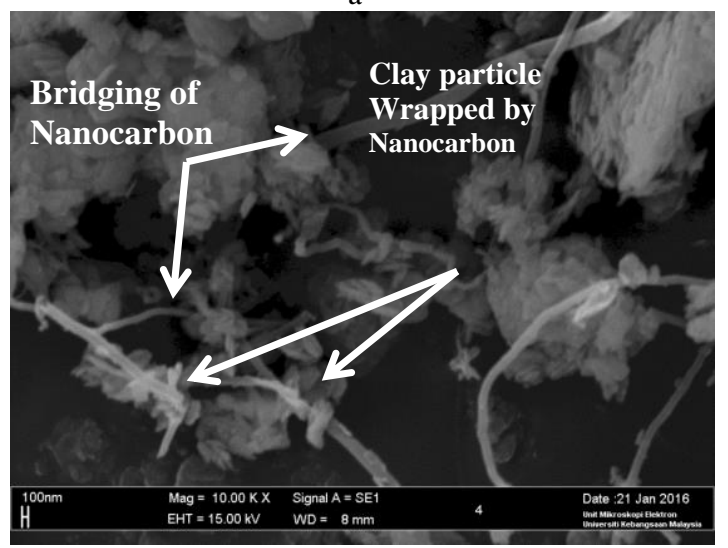

b
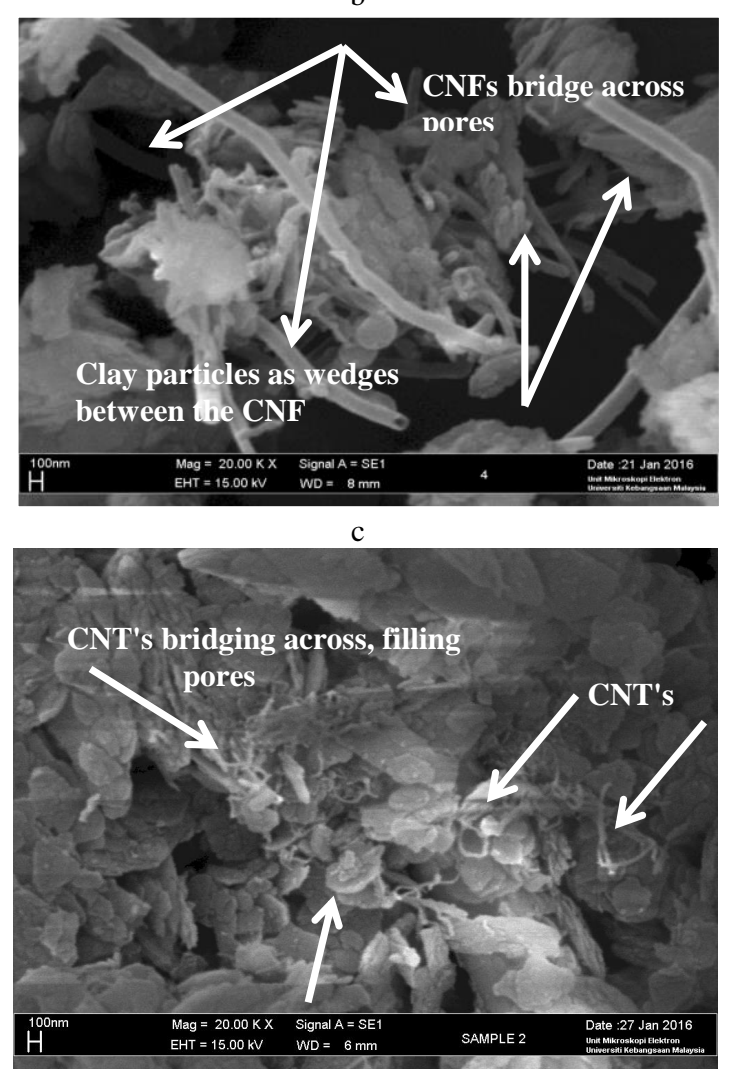

d

Fig. 7. FESEM images of soil and NCs: a, b, c-dispersed CNFs; $\mathrm{d}$-dispersed CNTs, after sonication

Fig. 8 shows that the soil particles that were smaller than approximately $250 \mathrm{~nm}$ were utilized to stabilize the 
CNTs and CNFs in the aqueous mixture without the use of surfactant.

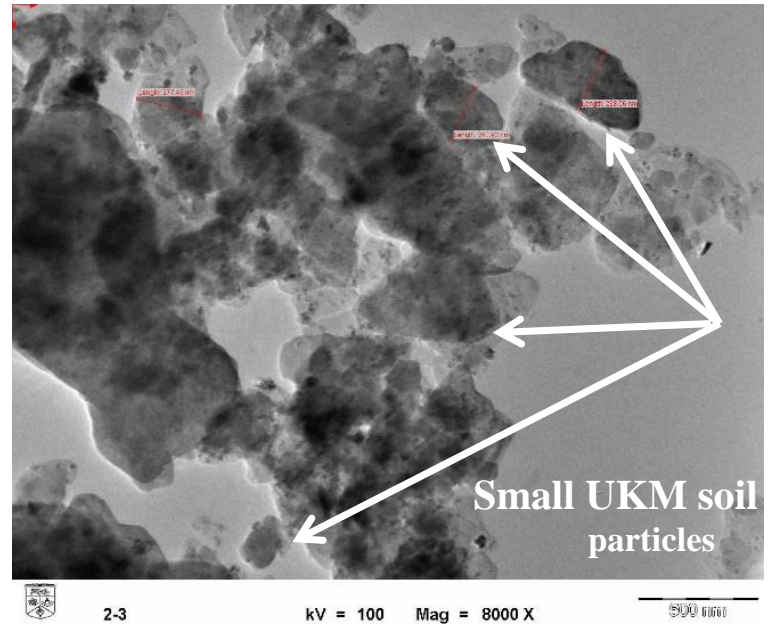

Fig. 8. TEM image of soil after $4 \mathrm{~min}$ of dispersion (sonication) in an aqueous solution

Fig. 9 shows that the particles of soil were significantly covered by CNTs and CNFs.
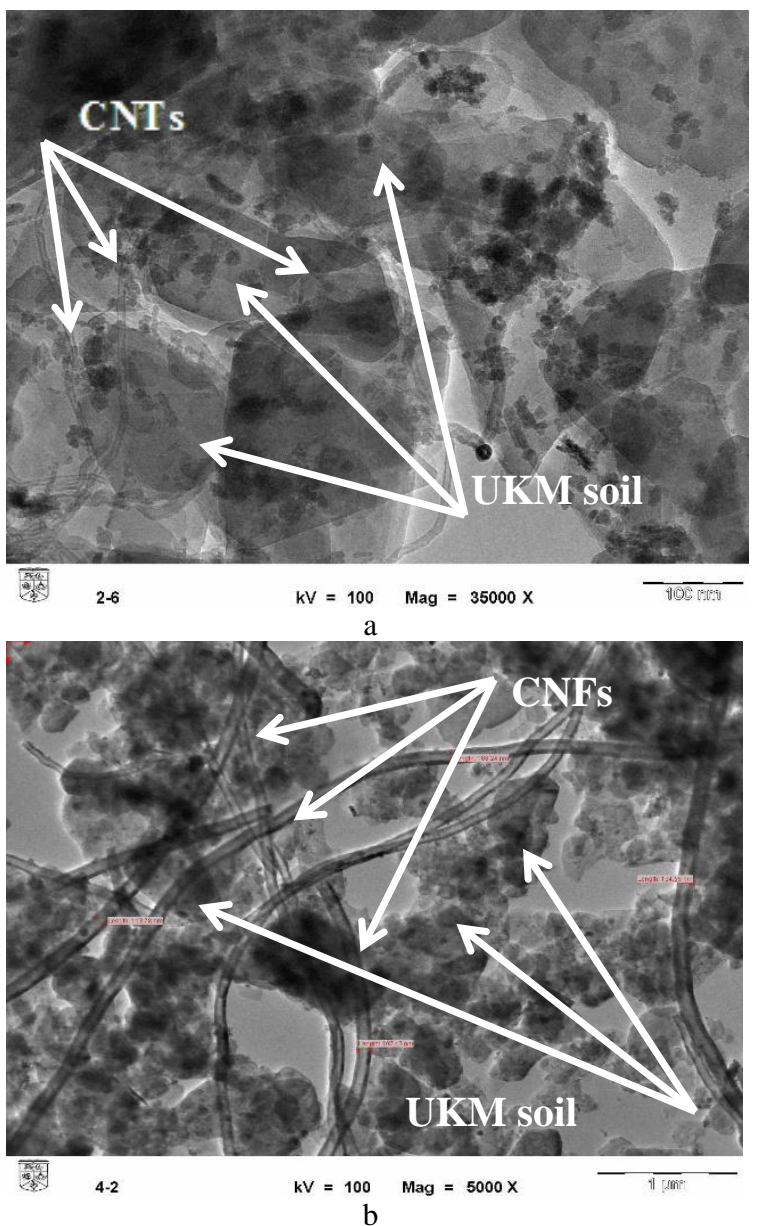

Fig. 9. TEM image of $\mathrm{NC}$ dispersed in soil and water 30 days after 4-minute sonication: $a-C N T s ; b-C N F s$. Clear intact walls is visible in the micrographs

The TEM investigation revealed a high degree of dispersion of the bundles as the sonication of 4 minutes was sufficient to cause most of the bundles to be exfoliated. Clear overlap between NCs and soil particles, with good dispersion, can be seen. Also, it is noticeable that the NCs bridge neighboring soil particles, thereby allowing better crack-bridging and interaction within the soil composite. Tight wrapping and overlapping due to sonication resulted in bridging across pores and wedging between the NCs. This likely explains the significant increase in the mechanical strength of nano-reinforced soil. As CNFs have a larger aspect ratio than CNTs, a correspondingly larger bond area within the soil composite was obtained, which would lead to better bonding between the CNFs and soil as shown in Fig. 9. Fig. 9 also illustrate that 4 minutes of horn sonication of CNTs and CNFs in a soil-water mixture will not damage the NCs. The originally highly-ordered NC walls did not snap, nor did they partially collapsed under the influence of the sonication. Any damage or shortening would have had adverse effects on the quality inducing undesirable changes to the mechanical behavior of the NCs when incorporated into composite structures [24]. The dispersion effect of ultrasonication on NCs is visible as they are clearly shown to cover small soil particles. Additionally, the figures show that NCs dispersed in the aqueous solution with individual strands distinctly isolated from each other.

As expected, it is clearly demonstrated that the $23 \%$ clay fraction of soil (particles smaller than $1 \mu \mathrm{m}$ ) prevented CNTs and CNFs from moving freely, thus restricting the ability of NCs to agglomerate. The potential for the NCs to intimately interact with the clay phases and affect the microstructure of the soil mixture after the sonication action, can be used to effectively stabilize and restrain the dispersion of CNFs in soil composite. With using this method to mixed soil with NCs it can be even improve the physical and mechanical properties of soil [25-29]. This finding also agrees with the hypotheses of Yazdanbakhsh and Grasley [18], Sanchez and Ince [30] who used silica fume particles $(<1 \mu \mathrm{m})$ to act as wedges between the CNFs thus physically keeping the particles far enough apart to render inter-fiber attractive forces ineffective. Their performance in structural and multifunctional composite materials should be further investigated.

\subsection{Effect of soil $\mathrm{pH}$ on dispersion nanocarbon}

The effect of soil $\mathrm{pH}$, before and after sonication is summarized in Table 2. The pH of NCs is slightly below 7 . This is acidic in nature, and thus, is not expected to raise the $\mathrm{pH}$ of UKM soil when compared to lime or cement is used for stabilization [31]. With a $\mathrm{pH}$ of 4.14, the soil is strongly acidic and can produce better dispersion of NCs due to the presence of hydrogen ions. Sparks [32] identified that acidity in soils originates from $\mathrm{H}^{+}$and $\mathrm{Al}^{+3}$ ions in the soil solution and sorbed onto soil surfaces. Even though $\mathrm{pH}$ strictly is a measure of $\mathrm{H}^{+}$ions in solution, $\mathrm{Al}^{+3}$ ions are also important in acidic soils because when the $\mathrm{pH}$ is between 4 and 6 , the $\mathrm{Al}^{+3}$ reacts with water $\left(\mathrm{H}_{2} \mathrm{O}\right)$ to form $\mathrm{AlOH}^{+2}$ and $\mathrm{Al}(\mathrm{OH})^{+2}$ as shown in Eq. 2. However, more $\mathrm{H}^{+}$ions are produced by $\mathrm{Al}^{+3}$ ion reaction as every $\mathrm{Al}^{+3}$ ion can create three $\mathrm{H}^{+}$ions. Many processes contribute to the formation of acid soils including rainfall, fertilizers use, plant root activity and the weathering of primary and secondary soil minerals. Acid soils can also be caused by pollutants such as acid rain and mine spoiling.

$\mathrm{Al}^{+3}+\mathrm{H}_{2} \mathrm{O} \rightarrow \mathrm{AlOH}^{+2}+\mathrm{Al}(\mathrm{OH})^{+2}$. 
Table 2. Effect of soil pH, before and after sonication

\begin{tabular}{|c|c|c|}
\hline Mix & $\mathrm{pH}$ before sonication & $\mathrm{pH}$ after sonication \\
\hline UKM soil & 4.14 & - \\
\hline CNT & 6.25 & 6.8 \\
\hline CNF & 6.2 & 6.5 \\
\hline $1: 1^{*}$ & - & 4.8 \\
\hline $1: 2^{*}$ & - & 4.65 \\
\hline $1: 4^{*}$ & - & 4.14 \\
\hline $1: 1^{\#}$ & - & 4.2 \\
\hline $1: 2^{\#}$ & - & 4.16 \\
\hline $1: 4^{\#}$ & - & 4.12 \\
\hline * soil to water ratio by weight with CNTs \\
\# soil to water ratio by weight with CNFs \\
\hline
\end{tabular}

In the same context, organic matter affects the amount of the living organisms in soil because these organisms consume humus [33]. Organic matter in the UKM soil was found to be $4.2 \%$. This organic matter is comprised primarily of humus or dead materials. Recent studies indicate that humus is composed of amphiphilic molecules having hydrophilic parts and a hydrophobic parts as end groups [34]. Therefore, the interaction between soil and other hydrophobic substances like CNTs or CNFs improves dispersion in water without need of adding additives such as surfactants.

\section{CONCLUSIONS}

Using a novel and simple approach of dispersion, it was shown that sufficient particles of size less than $1 \mu \mathrm{m}$ in soil can remarkably enhance the dispersion of CNTs and CNFs in the mixture by acting as a stabilizing agent that prevents reagglomeration of the NCs.

The use of small-sized soil particles for stabilizing NCs in soil materials is simple and practical, and can be readily implemented to improve soil properties. The study has shown that the adsorption of NCs by the clay fraction of the UKM soil resulted in good dispersion, which stabilized the dispersion of the CNTs and CNFs in the UKM soil, even 30 days after sonication.

FESEM and TEM imagery illustrated that the small soil particles were tightly wrapped and overlapped with NCs after sonication. This resulted in a bridging across pores and wedging between the NCs. The bridges across cracks and voids can produce high bonding strength between the NCs and UKM soil. It should be noted that CNFs had more workability than CNTs owing to their larger size. Furthermore, the UKM soil with $\mathrm{pH} 4.14$ (strong acid) produces better dispersion of NCs because the acidic solution increases the hydrogen ions without need for any additional chemical agent (surfactants).

This experimental study demonstrates the potential for NCs to interact with the clay fraction of soil and affect the microstructure and macroscopic properties of soil composites. The study also provides further understanding of the dispersion mechanism of NCs (CNTs and CNFs) in soil composites. It was demonstrated that performance enhancement of soil composites is possible if better dispersion of the NCs in the soil can be achieved. More work is needed to better understand the benefits and potential of NCs to improve the physical and mechanical properties of soil.

\section{Acknowledgments}

We acknowledge and appreciate the financial support and facilities provided by Geotechnical Engineering lab of UKM for this study as well as Fuel Cell Institute for (FESEM and TEM) tests and the Ministry of Higher Education (MOHE), Malaysia through Universiti Kebangsaan Malaysia (UKM) via research project code DPP-2014-047.

\section{REFERENCES}

1. Han, B., Wang, Y., Sun, S., Yu, X., Ou, J. Nanotip-Induced Ultrahigh Pressure-Sensitive Composites: Principles, Properties and Applications Composites Part A: Applied Science and Manufacturing 59 2014: pp. 105-114. https://doi.org/10.1016/j.compositesa.2014.01.005

2. Philip, B. The Perfect Nano-tubes Nature $382(18)$ 1996: pp. $207-208$. https://doi.org/10.1038/382207a0

3. Nochaiya, T., Chaipanich, A. Behavior of Multi-walled Carbon Nanotubes on the Porosity and Microstructure of Cement-based Materials Applied Surface Science 257 (6) 2011: pp. $1941-1945$. https://doi.org/10.1016/j.apsusc.2010.09.030

4. Wong, E.W., Sheehan, P.E., Lieber, C.M. Nanobeam Mechanics: Elasticity, Strength, and Toughness of Nanorods and Nanotubes Science 277 (5334) 1997: pp. 1971-1975. https://doi.org/10.1126/science.277.5334.1971

5. Yu, M.F., Lourie, O., Dyer, M.J., Moloni, K., Kelly, T.F., Ruoff, R.S. Strength and Breaking Mechanism of Multiwalled Carbon Nanotubes Under Tensile Load Science 287 (5453) 2000: pp. 637-640. https://doi.org/10.1126/science.287.5453.637

6. Yan, H., Gong, A., He, H., Zhou, J., Wei, Y., Lv, L. Adsorption of Microcystins by Carbon Nanotubes Chemosphere 62 (1) 2006: pp. 142-148. https://doi.org/10.1016/j.chemosphere.2005.03.075

7. Welch, C.R., Marcuson, W.F., Adiguzel, I. Will Supermolecules and Supercomputers Lead to Super Construction Materials? Civil Engineering 78 (11) 2008: pp. $42-52$. https://doi.org/10.1061/ciegag.0000201

8. Ravi, S., Vadukumpully, S. Sustainable Carbon Nanomaterials: Recent Advances and its Applications in Energy and Environmental Remediation Journal of Environmental Chemical Engineering 4(1) 2016: pp. $835-856$. https://doi.org/10.1016/j.jece.2015.11.026

9. Tyson, B.M., Abu, Al-Rub, R.K., Yazdanbakhsh, A., Grasley, Z. Carbon Nanotubes and Carbon Nanofibers for Enhancing the Mechanical Properties of Nanocomposite Cementitious Materials Journal of Materials in Civil Engineering 23 (7) 2011: pp. $1028-1035$. https://doi.org/10.1061/(ASCE)MT.1943-5533.0000266

10. Sobolkina, A., Mechtcherine, V., Khavrus, V., Maier, D., Mende, M., Ritschel, M., Leonhardt, A. Dispersion of Carbon Nanotubes and its Influence on the Mechanical Properties of the Cement Matrix Cement and Concrete Composites 34 (10) 2012: pp. 1104-1113. https://doi.org/10.1016/j.cemconcomp.2012.07.008

11. Taha, M.R., Ismail, E., Chik, Z., de Miguel, Y., Porro, A., Bartos, P. Some Nano Aspects and Concepts in 
Geotechnology Book Some Nano Aspects and Concepts in Geotechnology 2005: pp. 373-381.

12. Yazdanbakhsh, A., Grasley, Z., Tyson, B., Abu AlRub, R. Distribution of Carbon Nanofibers and Nanotubes in Cementitious Composites Journal of the Transportation Research Board 2142 2010: pp. 89-95. https://doi.org/10.3141/2142-13

13. Al-Rub, R.K.A., Tyson, B.M., Yazdanbakhsh, A., Grasley, Z. Mechanical Properties of Nanocomposite Cement Incorporating Surface-Treated and Untreated Carbon Nanotubes and Carbon Nanofibers Journal of Nanomechanics and Micromechanics 2(1) 2011: pp. 1-6. https://doi.org/10.1061/(ASCE)NM.2153-5477.0000041

14. Sadek, O., Mekhemer, W., Assaad, F., Mostafa, B. Adsorption of Poly (4-Sodium Styrene Sulfonate) on Kaolinite Clays Journal of Applied Polymer Science 100 (3) 2006: pp. $1712-1719$. https://doi.org/10.1002/app.21788

15. Tunç, S., Duman, O. The Effect of Different Molecular Weight of Poly(Ethylene Glycol) on the Electrokinetic and Rheological Properties of Na-Bentonite Suspensions Colloids and Surfaces A: Physicochemical and Engineering Aspects 317 (1-3) 2008: pp. 93-99. https://doi.org/10.1016/j.colsurfa.2007.09.039

16. Oweis, I.S., Khera, R.P. Geotechnology of Waste Management (2nd ed) PWS Publishing 1990. https://trove.nla.gov.au/version/46592756

17. Cui, L. Incorporation of Multiwalled Carbon Nanotubes to Ordinary Portland Cement (OPC): Effects on Mechanical Properties Advanced Materials Research 641-642 2013: pp. 436-439.

https://doi.org/10.4028/www.scientific.net/AMR.641-642.436

18. Yazdanbakhsh, A., Grasley, Z. Utilization of Silica Fume to Stabilize the Dispersion of Carbon Nanofilaments in Cement Paste Journal of Materials in Civil Engineering 26(7) 2014: pp. 06014010. https://doi.org/10.1061/(ASCE)MT.1943-5533.0001016

19. Vaisman, L., Marom, G., Wagner, H.D. Dispersions of Surface-Modified Carbon Nanotubes in Water-Soluble and Water-Insoluble Polymers Advanced Functional Materials 16 (3) 2006: pp. $357-363$.

https://doi.org/10.1002/adfm.200500142

20. Firoozi, A.A., Taha, M.R., Firoozi, A.A., Khan, T.A. Effect of Ultrasonic Treatment on Clay Microfabric Evaluation by Atomic Force Microscopy Measurement 66 2015: pp. 244-252. https://doi.org/10.1016/j.measurement.2015.02.033

21. Lee, J., Kim, M., Hong, C.K., Shim, S.E. Measurement of the Dispersion Stability of Pristine and Surface-Modified Multiwalled Carbon Nanotubes in Various Nonpolar and Polar Solvents Measurement Science and Technology 18 (12) 2007: pp. 3707-3712. https://doi:10.1088/0957-0233/18/12/005

22. Li, G.Y., Wang, P.M., Zhao, X. Mechanical Behavior and Microstructure of Cement Composites Incorporating SurfaceTreated Multi-Walled Carbon Nanotubes Carbon 43 (6) 2005: pp. $1239-1245$. https://doi.org/10.1016/j.carbon.2004.12.017

23. Han, B., Yang, Z., Shi, X., Yu, X. Transport Properties of Carbon-Nanotube/Cement Composites Journal of Materials Engineering and Performance 22 (1) 2013: pp. 184-189. https://doi.org/10.1007/s11665-012-0228-x

24. Dumée, L., Sears, K., Schütz, J., Finn, N., Duke, M., Gray, S. Influence of the Sonication Temperature on the Debundling Kinetics of Carbon Nanotubes in Propan-2-ol' Nanomaterials 3 (1) 2013: pp. 70-85. http://doi.org/ 10.3390/nano3010070

25. Alsharef, J., Taha, M.R., Firoozi, A.A., Govindasamy, P. Potential of Using Nanocarbons to Stabilize Weak Soils Applied and Environmental Soil Science 2016: pp. 9. http://dx.doi.org/10.1155/2016/5060531

26. Alsharef, J. M., Taha, M. R., Al-Mansob, R. A. \& Khan, T. A. Influence of Carbon Nanofibers on the Shear Strength and Comparing Cohesion of Direct Shear Test and AFM Journal of Nano Research 49 2017: pp. 108-126. https://doi.org/10.4028/www.scientific.net/jnanor.49.108

27. Taha, M. R. \& Alsharef, J. M. Performance of Soil Stabilized with Carbon Nanomaterials. Chemical Engineering Transactions. Italian Association of Chemical Engineering-AIDIC 63 2018: pp. 757-762. https://doi.org/10.3303/CET1863127

28. Taha, M. R., Alsharef, J. M., Al-Mansob, R. A. \& Khan, T. A. Effects of Nano-Carbon Reinforcement on the Swelling and Shrinkage Behaviour of Soil Sains Malaysiana 47 (1) 2018: pp. $195-205$. https://doi.org/10.17576/jsm-2018-4701-23

29. Mohd R. Taha, Jamal M. A. Alsharef, Tanveer A. Khan, Mubashir Aziz \& Gaber. M. Compressive and Tensile Strength Enhancement of Soft Soils Using Nanocarbons. Geomechanics and Engineering 16(5) 2018: 559-567. http://dx.doi.org/10.12989/gae.2018.16.5.559

30. Sanchez, F., Ince, C. Microstructure and Macroscopic Properties of Hybrid Carbon Nanofiber/Silica Fume Cement Composites Composites Science and Technology 69 (7) 2009: pp. $1310-1318$. https://doi.org/10.1016/j.compscitech.2009.03.006

31. Richman, D.L., Tucker, C.L., Koehler, P.G. Influence of Portland Cement Amendment on Soil pH and Residual Soil Termiticide Performance Pest Management Science 62 (12) 2006: pp. $1216-1223$. https://doi.org/10.1002/ps.1274

32. Sparks, D.L. Environmental soil chemistry Academic Press 978-0-12-656446-4 2003: pp. 352. https://doi.org/10.1016/B978-0-12-656446-4.X5000-2

33. Hamzah, Z., Amirudin, C.Y., Saat, A., Wood, A.K. Quantifying Soil Erosion and Deposition Rates in Tea Plantation Area, Cameron Highlands Malaysia Using 137 Cs The Malaysian Journal of Analytical Sciences 18 (1) 2014: 94-106.

34. Bohn, H.L., Strawn, D.G., O'Connor, G.A. Soil Chemistry. John Wiley \& Sons, 2015. 